\title{
Transapical aortic cannulation for cardiopulmonary bypass in type A aortic dissection operations
}

Shinichi Wada, MD, Shin Yamamoto, MD, PhD, Jiro Honda, MD, PhD, Akinori Hiramoto, MD, Hideichi Wada, MD, PhD, and Yasuyuki Hosoda, MD

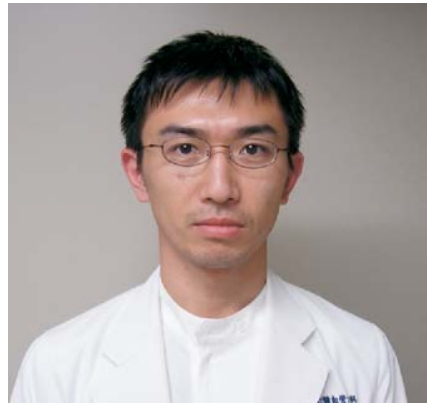

Dr Wada
From the Aortic Center, Kawasaki Saiwai Hospital, Kanagawa, Japan.

Received for publication March 12, 2006; revisions received April 16, 2006; accepted for publication April 24, 2006.

Address for reprints: Shinichi Wada, MD, Aortic Center, Kawasaki Saiwai Hospital, 39-1 Miyako-cho, Saiwai-ku, Kawasakishi, Kanagawa 212-0021, Japan (E-mail: swada-88@mtb.biglobe.ne.jp).

J Thorac Cardiovasc Surg 2006;132:369-72 $0022-5223 / \$ 32.00$

Copyright (C) 2006 by The American Association for Thoracic Surgery

doi:10.1016/j.jtcvs.2006.04.016
Objective: The femoral artery is the customary site for arterial cannulation for cardiopulmonary bypass in treating type A aortic dissections. However, because of concerns regarding complications caused by retrograde perfusion, the number of surgeons who prefer using the axillary artery as the site for cannulation is increasing. However, axillary artery cannulation also involves some problems. Thus we prefer transapical aortic cannulation for repair of type A aortic dissection.

Methods: Transapical aortic cannulation was performed in 138 patients ( 83 men and 55 women; mean age, 60.1 years; 129 acute and 9 chronic; 120 hemiarch repair and 15 total arch replacement) with type A aortic dissection. A 1-cm incision is made in the apex of the left ventricle, and a 7-mm soft and flexible cannula is passed through the apex and across the aortic valve until positioned in the ascending aorta transesophageal echocardiographic guidance.

Results: There were no cases in which conversion to cannulation of another artery was necessary. In all cases cardiopulmonary bypass flow was sufficient $(>2.5$ $\left.\mathrm{L} / \mathrm{m}^{-2} / \mathrm{min}^{-1}\right)$. There were no malperfusion events. Eight $(5.8 \%)$ patients had cerebrovascular accidents. Twenty-six (18.8\%) patients died in the hospital of complications not related to transapical aortic cannulation.

Conclusions: Our results show that transapical aortic cannulation is safe and useful for repair of type A aortic dissection. There are advantages to transapical aortic cannulation, such as simple and quick cannulation technique, sufficient antegrade aortic flow, and the reliability of true lumen perfusion with decreased risk of stroke and malperfusion.

$\mathrm{T}$ he femoral artery is the customary site for arterial cannulation for cardiopulmonary bypass in treating type A aortic dissections. However, possible complications caused by a retrograde blood stream from using the femoral artery as aortic return or caused by femoral artery complications are well known, such as cerebral embolization and organ malperfusion. ${ }^{1-5}$ Therefore the number of surgeons who prefer using the axillary artery instead of the femoral artery as the site for cannulation is increasing. However, axillary artery cannulation also involves problems because it requires a more precise technique and more time. If the axillary artery is small, cardiopulmonary bypass flow might be insufficient. ${ }^{6,7}$ Furthermore, if there is dissection of the subclavian artery with an intimal tear in the brachiocephalic or subclavian arteries, cannulation of the axillary artery can cause retrograde carotid dissection and cerebral malperfusion. ${ }^{8}$ Axillary artery cannulation is a good and useful method but is not always safe or reliable in the presence of acute aortic dissection. In contrast, transapical aortic cannulation has the advantage of avoiding these problems, such as antegrade blood stream, and involves a simpler and quicker cannulation technique..$^{9-11}$ Thus we prefer transapical aortic cannulation for repair of type A aortic dissection. 
TABLE 1. Clinical characteristics of patients with type A aortic dissection

\begin{tabular}{lc}
\hline Background & \\
Male/female sex & $83 / 55$ \\
Age (y) & $60.1 \pm 13.3(27-94)$ \\
Preoperative clinical condition (n) & $129 / 9$ \\
Acute/chronic & $8(5.8 \%)$ \\
Loss of consciousness* & $4(2.9 \%)$ \\
Hemiplegia & $64(46.4 \%)$ \\
Pericardial effusion & $23(16.7 \%)$ \\
Cardiac tamponade & $31(22.5 \%)$ \\
Aortic regurgitation $\geq 2$ & $33(23.9 \%)$ \\
Hemodynamic deterioration & \\
Organ ischemia & $6(4.3 \%)$ \\
Myocardial & $12(8.7 \%)$ \\
Cerebral & $3(2.2 \%)$ \\
Spinal & $5(3.6 \%)$ \\
Intestinalt & $7(5.1 \%)$ \\
Renal & $9(6.5 \%)$ \\
Lower extremities & \\
\hline
\end{tabular}

*Loss of consciousness on arrival: excludes transient loss of consciousness. $†$ Defined as signs of acute abdomen, such as abdominal pain, distension, or defense with severe metabolic acidosis.

TABLE 2. Operations performed with transapical aortic cannulation

\begin{tabular}{lr}
\hline Procedure $(\mathrm{n})$ & \\
Ascending aortic replacement & $3(2.2 \%)$ \\
Hemiarch repair & $120(87.0 \%)$ \\
Total arch replacement & $15(10.9 \%)$ \\
Concomitant procedure $(\mathrm{n})$ & \\
CABG & $21(15.2 \%)$ \\
Aortic valve suspension & $16(11.6 \%)$ \\
Aortic root reconstruction & $11(8.0 \%)$ \\
\hline
\end{tabular}

$C A B G$, Coronary artery bypass grafting.

We review our experience with this technique to evaluate the usefulness of transapical aortic cannulation for repair of type A aortic dissection.

\section{Patients and Methods}

Data were prospectively recorded in a database of consecutive patients who underwent operations performed by our team. The database was approved by the General Management Department of Kawasaki Saiwai Hospital. Between January 17, 1999, and February 20, 2006, transapical aortic cannulations were performed in 138 of 185 patients with type A aortic dissection. Transapical aortic cannnulation was performed basically for repair of type A aortic dissection, except in cases of severe aortic stenosis or prior aortic valve replacement, some reoperation cases, and some chronic cases in which direct ascending aortic cannulation was possible. Eightythree of 138 patients were male. The mean patient age was $60.1 \pm$ 13.3 years, ranging from 27 to 94 years. One hundred twenty-nine patients had acute ascending aortic dissection. Clinical back-

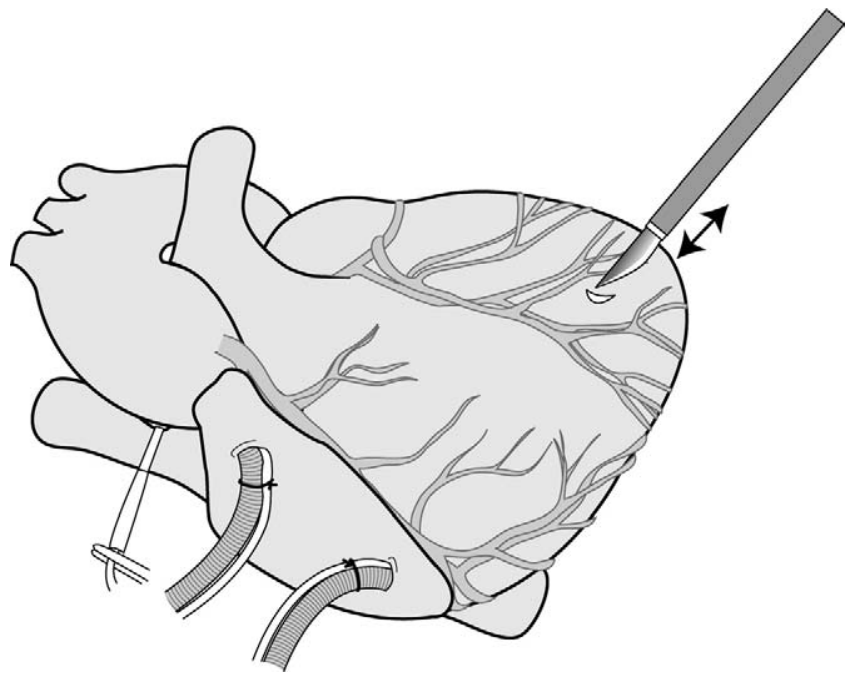

Figure 1. A 1-cm incision is made in the apex of the left ventricle without a purse-string suture.

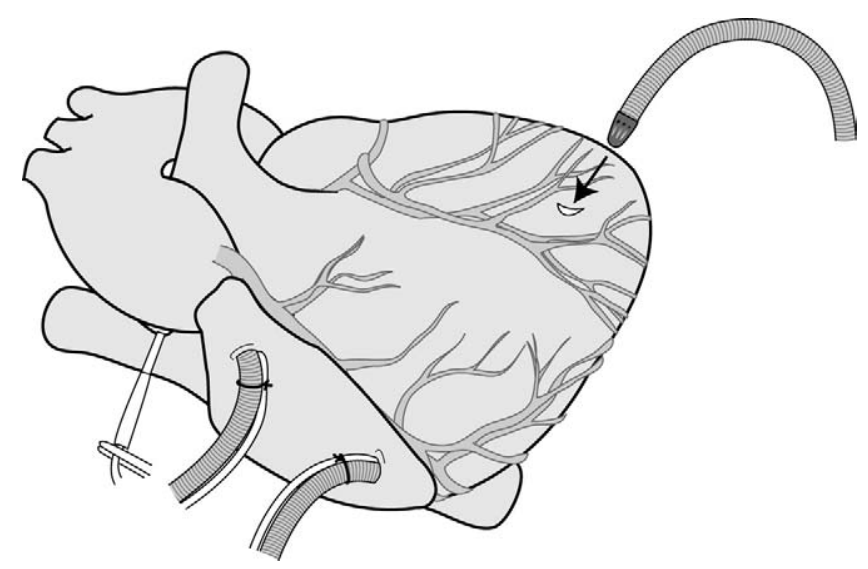

Figure 2. A 7-mm cannula (Sarns Soft-flow Extended Aortic cannula) is passed through the apex.

grounds and preoperative clinical conditions of the patients are presented in Table 1 . We basically performed hemiarch repair for acute aortic dissection type A. Hemiarch repair was performed in 120 patients, and total arch replacement was performed in 15 patients. Surgical procedures are presented in Table 2.

Our method is described below. After bicaval cannulation is performed for venous drainage, a $1-\mathrm{cm}$ incision is made in the apex of the left ventricle without a purse-string suture, and a 7-mm cannula (Sarns Soft-flow Extended Aortic cannula) with stylet is passed through the apex and across the aortic valve until positioned in the ascending aorta under transesophageal echocardiographic guidance (Figures 1-3). When the tip of the cannula is confirmed to be accurately situated in the true lumen under transesophageal echocardiographic guidance, cardiopulmonary bypass 


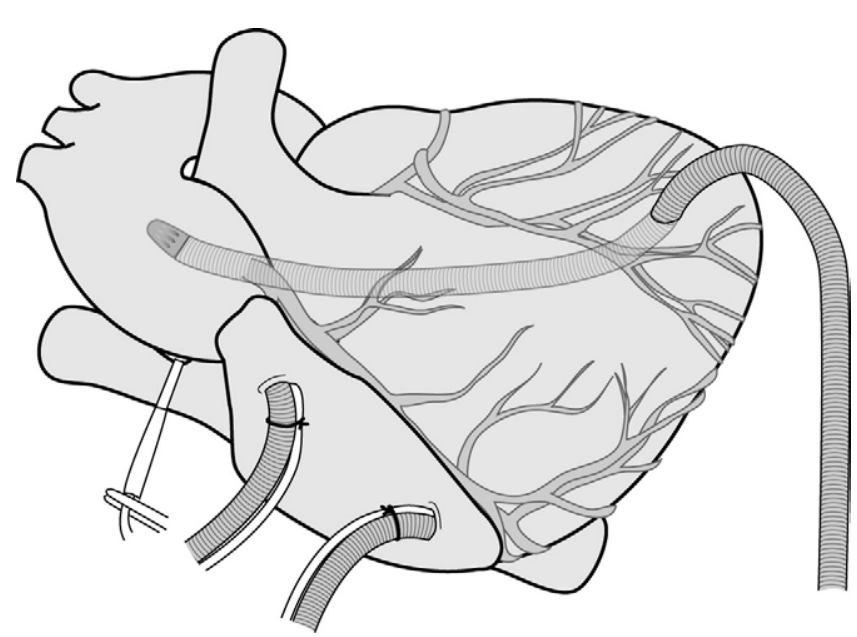

Figure 3. The cannula is passed across the aortic valve until positioned in the ascending aorta under transesophageal echocardiographic guidance.

is started. This procedure takes 10 seconds or so to start perfusion. A left ventricular vent is inserted through the right superior pulmonary vein.

For cerebral protection, we use deep hypothermic circulatory arrest with retrograde cerebral perfusion in all cases. Bladder and tympanic temperatures at circulatory arrest are $22^{\circ} \mathrm{C}$ and $17^{\circ} \mathrm{C}$, respectively. If the duration of circulatory arrest is prolonged, we use selective cerebral perfusion.

After circulatory arrest is achieved, the apical cannula is removed, open distal anastomosis is performed, and cardiopulmonary bypass is re-established through a $10-\mathrm{mm}$-diameter branch graft that is attached to the main tube graft. Then the incision in the left ventricular apex is closed with a few 4-0 polyvinylidene fluoride (Asflex, Crownjun) interrupted sutures with felt pledgets, and a proximal anastomosis is performed during rewarming.

\section{Results}

There were no cases in which conversion to cannulation through other arterial sites was necessary. In all cases cardiopulmonary bypass flow was sufficient $\left(>2.5 \mathrm{~L} / \mathrm{m}^{-2}\right.$ / $\left.\min ^{-1}\right)$. The mean total surgical time, cardiopulmonary bypass time, crossclamp time, and circulatory arrest time were $415 \pm 117$ minutes (median, 386 minutes), $233 \pm 68$ minutes (median, 222 minutes), $147 \pm 43$ minutes (median, 135 minutes), and $56 \pm 16$ minutes (median, 53 minutes), respectively.

There were no malperfusion events during cardiopulmonary bypass and no evidence of new intraoperative aortic regurgitation on transesophageal echocardiography after the cannula was inserted into the ascending aorta through the aortic valve. In the initial experience with this transapical aortic cannulation technique in which a purse-string suture was used, there was bleeding requiring the addition of further sutures at the incision on the apex in 3 cases. After
TABLE 3. Mortality

$\begin{array}{lc}\text { Hospital death } & 26(18.8 \%) \\ \text { Cause of death } & \\ \text { Cerebral bleeding } & 1 \\ \text { Cerebral infarction } & 4 \\ \text { Myocardial infarction } & 6 \\ \text { Gl ischemia } & 4 \\ \text { Lower extremities ischemia } & 3 \\ \text { Rupture (descending aorta) } & 3 \\ \text { Low output syndrome } & 2 \\ \text { Infection (mediastinitis) } & 1 \\ \text { Respiratory failure } & 1 \\ \text { Unknown } & 1\end{array}$

GI, Gastrointestinal.

starting to perform simple stab-wound cannulation for transapical aortic cannulation, there were no further bleeding problems requiring further sutures.

Eight patients had cerebrovascular accidents, defined as a permanent central neurologic deficit thought to have occurred preoperatively or intraoperatively. Spinal cord ischemia was not included. Five of 8 patients had demonstrated episodes of consciousness loss preoperatively. Five of 8 patients with stroke died during the postoperative hospital stay.

Twenty-six patients who died in the hospital of complications not related to transapical aortic cannulation are presented in Table 3. The most frequent causes of these hospital deaths were organ ischemia caused by preoperative malperfusion. All of the cases of cerebral bleeding, organ (cerebral, myocardial, gastrointestinal, and lower extremities) ischemia, and low output syndrome causing hospital deaths existed preoperatively. Ruptures of the descending aorta, infection, respiratory failure, and sudden death of unknown cause occurred in the late postoperative period. None of the hospital deaths were related to intraoperative malperfusion, embolization, or cannulation problems particular to this technique of apical cannulation.

\section{Discussion}

Our results showed that transapical aortic cannulation is safe and useful for repair of type A aortic dissection. The advantages of transapical aortic cannulation are thought to be as follows: simple and quick cannulation technique, sufficient antegrade aortic flow, and secured true lumen perfusion with decreased risk of embolization and malperfusion.

Transapical aortic cannulation is a very simple and quick procedure, taking only 10 seconds or so to perform. Femoral or axillary artery cannulation requires another skin incision in addition to median sternotomy and requires more time to perform more complicated procedures. Axillary artery cannulation is an excellent and useful arterial approach, but it might cause local complications, ${ }^{7}$ including dissection of 
the artery ${ }^{8}$ and insufficient flow, and often requires a side graft sewn to the vessel. ${ }^{6,7}$

By using the transapical aortic cannulation technique, sufficient antegrade aortic flow and the reliability of true lumen perfusion is provided. There were no cases in which conversion to cannulation of another artery was necessary. In all cases cardiopulmonary bypass flow was sufficient $\left(>2.5 \mathrm{~L} / \mathrm{m}^{-2} / \mathrm{min}^{-1}\right)$. With femoral or axillary cannulation, some patients can be perfused inadequately. The insufficient perfusion of patients is related to a small axillary artery in axillary artery cannulation, ${ }^{6,7}$ whereas in femoral cannulation malperfusion caused by false lumen perfusion or the occasional presence of aortoiliac occlusive disease is a major problem. ${ }^{1,4,12}$ In transapical aortic cannulation, true lumen perfusion can always be secured because we place the cannula tip in the true lumen of the ascending aorta under transesophageal echocardiographic guidance.

We considered the rate of stroke in transapical aortic cannulation to be low. It is reported that stroke occurs in about $6 \%$ to $7 \%$ of adult cardioaortic procedures during circulatory arrest ${ }^{5,13}$ and in $10.7 \%$ of axillary artery cannulations for aortic diseases or reoperation. ${ }^{7}$ Some of the risk factors for these strokes were emergency operation and aortic dissection. ${ }^{5,13}$ Especially in emergency operations on the thoracic aorta, stroke occurred in $16.5 \% .^{5}$ In our experience, although almost all of the procedures were performed as emergencies for acute aortic dissection, stroke occurred in only $5.8 \%$.

Securing true lumen perfusion with this method decreased the risk of embolization and malperfusion. Almost all of the deaths were caused by organ ischemia from malperfusion existing before the operation. The other causes of death developed in the late postoperative period. None of the causes of hospital death were related to this cannulation technique.

Transapical aortic cannulation has some problems. First, this technique is not practical for use in patients with severe aortic stenosis or after cardiovascular surgery with median sternotomy. In patients with severe aortic stenosis, the cannula might completely occlude the aortic orifice. In patients undergoing previous cardiovascular surgery through a median sternotomy, it is difficult and takes more time to establish transapical cannulation because of cardiac adhesion. Second, bleeding at the access site of the apex is a serious problem. In our initial experience with this technique in which a purse-string suture was used, there was bleeding requiring the addition of further sutures at the incision on the apex in 3 cases. After starting to perform simple stab-wound cannulation for transapical aortic cannulation and closing the incision with a few 4-0 polyvinylidene fluoride interrupted sutures with felt pledgets, there were no further bleeding problems requiring additional su- tures. Although transapical aortic cannulation does involve these problems, there is no arterial inflow site that is always safe or reliable in the presence of acute aortic dissection.

Transapical aortic cannulation is an old technique that was initially described in the early $1970 s .{ }^{10}$ Although this technique seems to be very simple, quick, and safe, its use was limited to a very few patients, such as those with severely calcified ascending aortas ${ }^{14}$ and in pediatric patients with dilated main pulmonary arteries covering the whole ascending aorta. ${ }^{15} \mathrm{We}$ consider that the indications for transapical aortic cannulation should be extended.

In conclusion, our study showed that transapical aortic cannulation is a safe and useful technique for establishing cardiopulmonary bypass for repair of type A aortic dissection.

\section{References}

1. Van Arsdell GS, David TE, Butany J. Autopsies in acute type A aortic dissection: surgical implications. Circulation. 1998;98(suppl):II299-304.

2. Price DL, Harris J. Cholesterol emboli in cerebral arteries as a complication of retrograde aortic perfusion during cardiac surgery. Neurology. 1970;20:1209-14.

3. Martin WR, Hashimoto SA. Stroke in coronary artery bypass surgery. Can J Neurol Sci. 1982;9:21-6.

4. Robicsek F, Guarino RL. Compressing of the true lumen by retrograde perfusion during repair of aortic dissection. J Cardiovasc Surg. 1985 26:36-40.

5. Goldstein LJ, Davies RR, Rizzo JA, Davila JJ, Cooperberg MR, Shaw RK, et al. Stroke in surgery of the thoracic aorta: incidence, impact, etiology, and prevention. J Thorac Cardiovasc Surg. 2001;122:935-45.

6. Schachner T, Vertacnik K, Laufer G, Bonatti J. Axillary artery cannulation in surgery of the ascending aorta and the aortic arch. Eur J Cardiothorac Surg. 2002;22:445-7.

7. Sinclair MC, Singer RL, Manley NJ, Montesano RM. Cannulation of the axillary artery for cardiopulmonary bypass: safeguards and pitfalls Ann Thorac Surg. 2003;75:931-4.

8. Imanaka K, Kyo S, Tanabe H, Ohuchi H, Asano H, Yokote Y. Fatal intraoperative dissection of the innominate artery due to perfusion through the right axillary artery. J Thorac Cardiovasc Surg. 2000;120: 405-6.

9. Yamamoto S, Hosoda Y, Yamasaki M, Ishikawa N, Fuchimoto K, Fukuda T. Transapical aortic cannulation for acute aortic dissection to prevent malperfusion and cerebral complications. Tex Heart Inst J. 2001;28:42-3.

10. Zwart HH, Kralios A, Kwan-Gett CS, Backman DK, Foote JL, Andrade JD, et al. First clinical application of transarterial closed-chest left ventricular (TaCLV) bypass. Trans Am Soc Artif Intern Organs. 1970;16:386-91.

11. Flege JB, Aberg T. Transventricular aortic cannulation for repair of aortic dissection. Ann Thorac Surg. 2001;72:955-6.

12. Fusco DS, Shaw RK, Tranquilli M, Kopf GS, Elefteriades JA. Femoral cannulation is safe for type A dissection repair. Ann Thorac Surg. 2004;78:1285-9.

13. Svensson LG, Blackstone EH, Rajeswaran J, Sabik JF, Lytle BW, Gonzalez-Stawinski G, et al. Does the arterial cannulation site for circulatory arrest influence stroke risk? Ann Thorac Surg. 2004;78: 1274-84.

14. Golding LAR. New cannulation technique for the severely calcified ascending aorta. J Thorac Cardiovasc Surg. 1985;90:626-7.

15. Watanabe H, Eguchi S, Miyamura H, Hayashi J, Ohzeki H, Sugawara M, et al. Transapical aortic cannulation in pediatric patients. Ann Thorac Surg. 1997;63:1149-50. 